\title{
Definition of the CIE standard skies and application of high dynamic range imaging technique to characterize the spatial distribution of daylight in Chile
}

\author{
Definición de cielos CIE estándar y aplicación de fotografías de alto rango dinámico para \\ caracterizar la distribución espacial de luz natural en chile
}

Maria Beatriz Piderit (Main and Contact Author)

Universidad del Bio-Bio, Facultad de Arquitectura Const. y

Diseño, Depto. Diseño y Teoría de la Arq., Chile

mpiderit@ubiobio.cl

Av. Collao 1202, Concepción, Chile, CP 4051381, +56 423111409

Coralie Cauwerts

Université Catholique de Louvain,

Architecture et climat, Bélgica

coralie.cauwerts@uclouvain.be

\section{Resumen}

La efectividad y precisión de un estudio de iluminación natural depende de conocer las condiciones de clima y la luz disponibles en un lugar, para así evaluar la iluminancia obtenida durante el proceso proyectual. Se presentan las metodologías aplicadas de una investigación realizada cuyo objetivo fue conocer y entregar datos realistas de la distribución espacial de los cielos, para así construir las bases para futuros estudios de iluminación en Chile. Se inicia con una revisión de las métricas para cuantificar la luz natural; posteriormente se presenta la metodología utilizada para levantar la información de frecuencias mes a mes en cuatro tipos de cielos CIE estándar a partir de archivos meteorológicos. Finalmente, se expone el método de fotografías de alto rango dinámico (High Dynamic Range-HDR) aplicado para conocer la distribución espacial de los cielos de seis ciudades de Chile. Se concluye que conocer los cielos $\mathrm{CIE}$ estándar posibilita focalizar los estudios de iluminación natural para cielos predeterminados, realizando un diseño y análisis para los cielos más frecuentes. Así mismo, el método aplicado para caracterizar la distribución espacial de los cielos debe ser calibrado para cada localidad de estudio.

Palabras claves: Luz Natural, modelos de cielo $\mathrm{CIE}$, distribución de iluminancia del cielo, fotografía de alto rango dinámico, captura del cielo

\section{Introduction}

Daylight is an essential source of lighting in buildings. The luminous spectrum of daylight provides a greater feeling of well-being and comfort for the occupants, positively affecting production and concentration, thus being preferable over artificial lighting. Not achieving a good light quality, because of an excess or lack of light, leads to visual discomfort, glare or fatigue. Five minutes of direct sunlight lead the occupants to close the curtains and to turn on the lights for hours (Anderson, 2014), unnecessarily having the artificial light on, ignoring the principle of energy saving and efficiency. Knowing the available daylight allows designing spaces that provide greater comfort for the occupants and energy savings on artificial light and/or in the cooling systems.

Sustainable architecture presents the idea of using passive tools to achieve comfort. Daylight is the main source of lighting whose most important objective is providing the necessary light for visual tasks and visual comfort. To reach this objective, we must carry out a study and analysis of daylight contributions accurately. The variability and
Muriel Diaz

CITEC-Universidad del Bio-Bio, Chile madiazc@ubiobio.cl

Manuscript Code: 0446

Date of reception/acceptation: 01sep2014/01dec2014

\begin{abstract}
The effectiveness and accuracy of a daylighting study relies on knowing the climate and light conditions available at a given place, to then evaluate the illuminance obtained during the project development process. This paper presents the methodologies of a research process, whose objective is providing realistic data to establish the foundations for future lighting studies in Chile. It starts with the revision of the metrics used to quantify daylight; later, the methodology used to collate the monthly frequencies on four types of standard CIE skies, starting from climate files, is presented. Finally, both the methodology and the results obtained are presented to measure and characterize the real skies, as well as the High Dynamic Range photographs (HDR) and, as complement of this information, the illuminances measurements of the sky dome to define the types of skies of six Chilean cities. From the study applied, it is possible to conclude that knowing the standard CIE skies of a place allows us to adjust and focus the daylighting study for predetermined and predominant skies. It is just as important to mention that the measuring techniques for the skies must be adjusted and calibrated for each studied location.
\end{abstract}

Keywords: Daylighting, CIE sky models, sky iluminance distribution, high dynamic range photography, capture sky dome.

dynamism of light makes its prediction difficult, since it depends on the climate conditions, the types of skies, the season and the time of the day.

To carry out a daylight study it is necessary to know the daylight metrics, as well as the principles, advantages and limitations in order to know which one of these to use. Knowing the light conditions of each place, the different types, frequency and predominance of skies during the months and/or seasons of the year is just as important. Having this information allows that, on carrying out lighting studies, simplified evaluations are used in the process of designing and evaluating the metrics to be used. Finally, it would be ideal to know the spatial distribution and the real illuminance contribution of these skies in a given study location. With this information, we can generate the foundations for a daylighting study. 


\section{Description of the problem}

The purpose of this research is to build the foundation for future daylighting studies in Chile, approaching the aforementioned aspects. The first part of the research consists of a revision of daylighting indicators. The second part presents the data analysis, which allowed defining the sky condition of several cities according to standard CIE skies, and their monthly frequencies. Finally, the real and standard sky conditions were collated through the analysis of illuminances maps built with High Dynamic Range (HDR) images and thus get to know the spatial distribution of the sky.

Chile is a long country $(4,400 \mathrm{~km}$ in length) with different climatic conditions. Regarding daylighting design, there is a lack of studies that allow predicting the sky conditions in different locations, a situation that becomes relevant when the country's climatic diversity is considered. The weather data that can be obtained from climate databases, such as EnergyPlus, Meteonorm among others, provides the necessary data for the thermal simulations, but does not consider the types and probabilities of sky occurrences. Therefore, the purpose of this research is providing such information. Data on the frequency of the standard CIE skies would serve as a guide for the lighting analysis done by architects and/or by lighting specialists, allowing the designer to identify the predominant skies (i.e., those with greater influence on the climate) and applying them to the daylighting simulations. The application of the HDR photography method allows evaluating their feasibility and applicability on the daylighting studies.

The final objective of this research is to provide analytical tools that contribute to enriching knowledge in terms of factors that have an impact on the available daylight, incorporating dynamic aspects of light such as its variation through time, in order to promote dynamic studies of daylighting in Chile.

\section{Daylighting Metrics}

When facing a daylight study it is important to clearly know what we wish to evaluate, what aspects will be evaluated such as the luminance $\left(\mathrm{cd} / \mathrm{m}^{2}\right)$, illuminance (lux), uniformity, among others, aside from knowing the metrics we have available to carry out this evaluation. For this, it is relevant to review the different metrics used in daylight studies, the concepts that are integrated and how these are applied. Through time, it has been possible to obtain the different metrics through simple calculations or even with more complex calculations. Nowadays, dynamic metrics are preferred, since they allow integrating the weather conditions, the different types of skies and their variability.

The most commonly used indicator in daylighting, developed over 50 years ago, is the Daylighting Factor - DF, a static indicator which expresses the relationship between the interior horizontal lighting (work plane) and exterior global illuminance (unobstructed), simultaneously measured for an overcast CIE sky design (Moon, P.; Spencer, 1942). The original reason to use this indicator based on percentages was to avoid fluctuations in daylight intensity (Waldram, 1950). In respect to this indicator, Reinhart (2006) explains that, in the beginning, it was used as a compliance test for a minimum legal requirement and was not thought as an indicator to predict or evaluate a design. Its greatest limitation is that, for its determination, the orientation and time of the day are not considered and it is only used with an overcast sky design. This condition does not fit all climates, especially in those parts of Chile where clear skies are the most predominant. Designing from the daylighting factor (DF) may lead to serious design problems by underestimating light availability, which suggests designing facades with too much glass, leading to inside overheating and glare most of the time. Also, by not considering the orientation, the design of the facades will be identical, which goes against the precepts of passive design.

The development of weather databases allows developing metrics to evaluate lighting starting from the typical climatic conditions of a particular place. Climate based daylight modeling (CBDM) considers the quality and amount of daylight and solar availability. The metrics developed and used in measuring daylight dynamic performance are based on the time interval where the reference levels of illuminance inside a building are reached. These time intervals extend, normally, throughout the whole year, based on external data like annual solar radiation, according to the location of the building. The key advantage of these daylight dynamic performance metrics, compared to the static measurements, is that for a given building they consider the amount and character of the daily and seasonal daylight variations, together with irregular weather data (Reinhart, Mardaljevic, \& Rogers, 2006).

The first CBDM metric was Daylight Autonomy (DA), originally proposed by the Swiss Association of Electricians in 1989 and adapted by Reinhart in 2006. This was integrated into the Daysim software and we can currently obtain it through Radiance commands or through Rhino's DIVA tool. This indicator refers to the percentage of time in which a minimum illuminance level of interior daylighting is kept; generally it was defined according to the visual task at hand. The required illuminance value is defined by the designer, usually following regulatory requirements or manuals like the IESNA Handbook or others. Its advantage is that it allows the prediction of daylight throughout the year on a given spot or grid for a time interval of one hour or 5 minutes, considering all sky conditions during the year (Reinhart et al., 2006). Also, it allows simulating the building at a specific location with a certain climate and considering the orientation of the building. Since Daylight Autonomy expresses the percentage of time on which each point of the grid allows carrying out the required visual task using only daylight, it is a correct indicator for estimating energy consumption. However, it does not consider the moments when too much daylight is provided, meaning that it is possible to reach a good level of autonomy - DA $(100 \%)$ and at the same time have visual discomfort, due to excesses of daylight with illuminance level higher than 3000 lux.

In 2006, Rogers proposed the Continuous Daylight Autonomy (DAcon), which is a metric that provides percentage credits when the daylight levels are below the expected illuminance value. It provides flexibility to the DA calculation because there is a transition between compliance and noncompliance. To evaluate glare it defines a second indicator called Maximum Daylight Autonomy (DAmax), to indicate the percentage of hours where the influence of sunlight is excessive (Reinhart et al., 2006).

Mardaljevic and Nabil proposed a modification, integrating Daylight Autonomy (DA) with Maximum Daylight Autonomy (DAmax). Considering that daylight illuminances in real time 
present great variations, this considers daylight's own variability integrating series of illuminances targets, leaving the concept of threshold behind, obtaining compliance objective with one fixed illuminance value (i.e. 300 lux or another). The purpose of Useful Daylight Autonomy (UDI) is integrating the possible points on the work plane which will have too much or too little daylight into the analysis, defining the series of "useful" illuminances levels for the occupants. In the beginning, the useful range was defined between 100 and 2000 lux; this range, considered as a compliance, gets a score, while the levels below ( $<100$ lux) and over ( $>2,000$ lux) do not get a score (Nabil \& Mardaljevic, 2006). In 2012, the ranges were modified based on surveys made on office buildings, defining as useful the range between 100 and 3,000 lux, where credits are assigned; the values under the useful range called UDI fell short (or UDI-f $<100$ lux) and the levels above called UDI exceeded (or UDI-e $>3,000$ lux) are not assigned credits. Here the useful range was subdivided: UDI supplementary (or UDI-a) within 100 to 300 lux, UDI autonomus (UDI-a) illuminance between 300 - 3000 lux and UDI combined (or UDI-c) with values $>100$ lux and $<3000$ lux. For illuminance levels of UDI-c, additional artificial lighting may be necessary to complement daylight for common tasks such as reading, and for autonomous UDI, additional artificial lighting is likely to be unnecessary (Mardaljevic et al., 2012). This metric integrates a new concept in daylight evaluation: the concept of illuminance target range, which requires defining the top and bottom illuminance thresholds.

A methodology that considers the frequency and the types of skies was developed by Andersen et al. (2008a) for Lightsolve, and consists of a time segmentation method which reasonably divides up the year. It starts by averaging the data per typical Weather Year hour (TMY2) through a limited number of periods, during which the positions of the sun and the climate conditions are similar using the ASRC-CIE sky model developed by Perez, determining the illuminance in each moment for each one of the four standard CIE sky models (overcast, intermediate, clear turbid, clear). The resulting illuminance values are added and weighted according to the occurrence of the type of sky during that period (Andersen et al., 2008b). The described method can be applied upon knowing the frequencies and the types of skies.

This revision presents several alternatives that allow addressing the daylight studies, starting from the daylight factor and finally presenting dynamic metrics, which allows carrying out more integrated evaluations. These metrics are integrated into advanced software; however, it is possible to evaluate them in the pre-design stage using simpler software such as Ecotect, Velux Daylighting Visualizer, Designbuilder, Daysim, among others. Knowing the predominant skies of a location where the design is taking place allows using the predominant sky to carry out the simulation and, in a later stage, evaluating following the aforementioned metrics, defining which one to consider and how to obtain it according to our knowledge. Providing the information of the types and frequencies of the skies will help define passive design strategies to be integrated, leading to the second part of the research.

\section{Standard CIE skies in Chile}

Upon designing and simulating daylight, the characteristics of the predominant sky, i.e., the type of sky of a place, are determining, which means understanding and defining the light source, the sun and the sky considering also that the altitude of the sun and its angle of influence vary throughout the day and the different seasons. Daylighting coming through a window or opening or oriented towards a specific direction results from a combination of the direct component coming from the sun and the diffuse component reflecting off the atmosphere, water vapor, clouds and the environment. When facing a daylight study it is relevant to know the characteristics, types and frequencies of the skies in the different periods and thus carry out a lighting study focused on the real lighting conditions. The type of sky is conclusive in the result of a simulation; we can have variations of luminous intensity from a completely clear sky, intermediate sky or overcast sky resulting in divergent results that can lead to wrong design decision-making which, for example, can cause overheating in the summer because of excessive solar gains.

Researchers have designed a theoretical framework for different sky models which allows building and characterizing the skies starting from luminance distribution, and the clearness and brightness of the sky (Perez, Ineichen, Seals, Michalsky \& Stewart, 1990). The Commission International de I'Eclairage (CIE) defines the characteristics of the skies most commonly used in simulations which allows building a sky dome to provide real context to 3D models for lighting simulations. As mentioned above, these are overcast sky, intermediate sky, clear turbid sky and clear (Commission International de l'Eclairage, 2003), shown in Figure 1 and described below:

a) Overcast skies (Hopkinson, Petherbridge, \& Longmore, 1966): this type of sky is completely covered by clouds and the view of the sun is completely impeded. Under a very overcast condition, there is little to no direct lighting and the values of global and diffuse illuminance are very close.

b) Intermediate sky (Igawa, Nakamura, Matsuura, \& Prof, 1997): this is a type of sky found between the clear and the overcast skies. Since the intermediate sky type broadly varies according to the appearance of the sun, the shape of the clouds and the amount of clouds, the distribution of the intermediate sky's luminance is more complex than that of the clear and overcast skies.

c) Clear turbid sky (CIE, 2003): this is the clear sky with a high turbidity factor, understanding this turbidity factor as cloudiness or fog.

d) Clear sky (CIE, 2003) varies according to the altitude and azimuth of the sun, is brighter and closer to the sun and attenuates when moving away from it. The brightness of the horizon is between these two extremes.

The ASRC-CIE model (Perez, Ineichen, Seals, Michalsky, \& Stewart, 1990) defines the four types of skies based on their luminances and distribution, which allows stating that this model is the most appropriate to obtain the time, frequency and average in which these occur, realistically. In 1994, Littlefair also concluded that the ASRC-CIE model is the most complex one, as this allows adapting it to a larger range of climate zones (Andersen et al., 2008a). As in Lightsolve, we used this model, where the clearness and brightness are used to build a real sky that is a linear combination to determine weighting factors for each one of the four CIE skies.

The methodology presented here allows generating the models of the different types of skies for daylight simulations based on weather files created for thermal simulations. The 
files of the standard year for dynamic thermal simulation can be downloaded from several databases. One the most complete banks is the one compiled to be used with the EnergyPlus thermal simulation software, where we can find data for Antofagasta, Santiago, Concepcion and Punta Arenas; for other cities of interest, like lquique and Coyhaique, ".epw" files were obtained from the Meteonorm 7.0 software. From the climate files obtained, a revision of hourly data was done considering the horizontal illuminance and diffuse global illuminance, to determine the direct normal illuminance and thus define the four standards types of CIE skies.

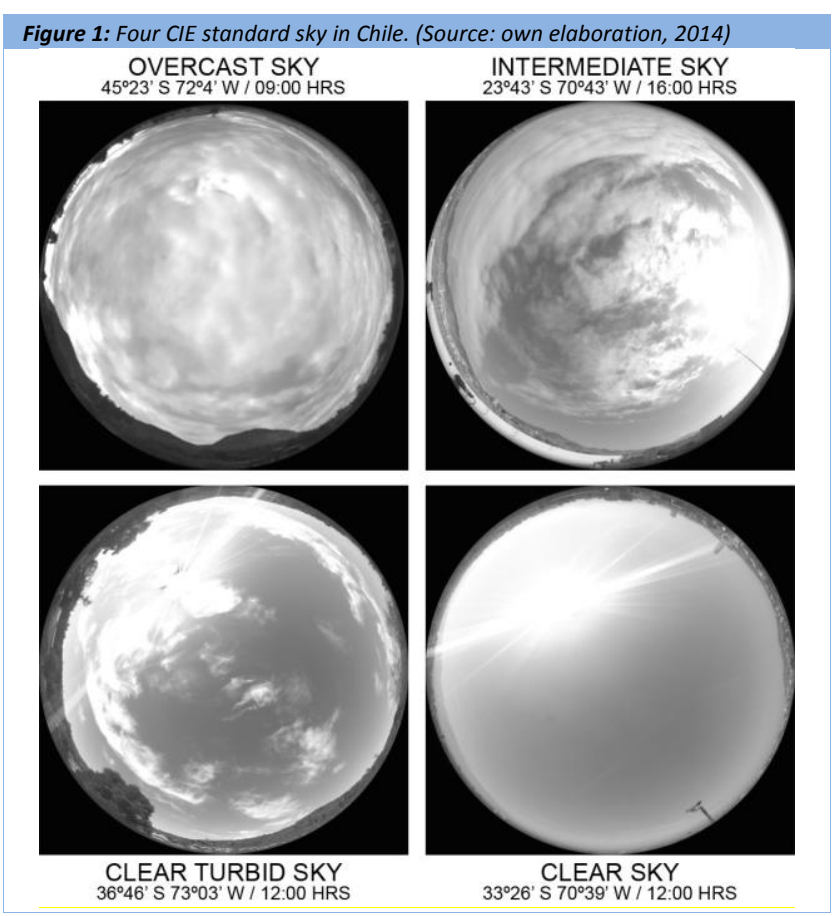

The climate files were read with a MATLAB script to obtain a set of indexes that allowed us to get - according to the latitude, longitude, time of the year, solar time, horizontal global illuminance and horizontal diffuse illuminance - the solar altitude, the solar angle of the zenith (Z), necessary to determine the epsilon $(\varepsilon)$ coefficient which determines the sky clearness and delta $(\delta)$ which defines sky brightness. To determine the value of epsilon, the Equation 1 (Eq 1) defined by the ASRC-CIE model was used (EC 1 ). Where $\mathbf{Z}$ corresponds to $1 / 2$ - radians, Eed to the diffuse horizontal irradiance and Ees to the direct normal irradiance.

$$
\varepsilon=\left[(\text { Eed }+ \text { Ees }) / \text { Eed }+1,041 Z^{3}\right] /\left[1+1.041 Z^{3}\right]
$$

Perez defines eight intervals based on the epsilon $(\varepsilon)$ coefficient. The first intervals correspond to the overcast condition and the last to very clear skies, the clear sky being on the eighth interval of $\varepsilon$ (Perez, Seals, \& Michalsky, 1993). The brightness and occurrence of the different skies in the different moments is considered, to then average them to obtain the frequencies of each one of them. Sky clearness and sky brightness are evaluated based on pairs of skies in a given moment. Starting from the clearness given by $\varepsilon$ we could have overcast or intermediate PAIR, the value of $\delta$ would define which sky PAIR it corresponded to, the same for the clear sky and the clear-turbid sky (Kleindienst, Sian, Andersen, Marilyne, Bodart, 2008).

Table 1: Frequencies and predominance of the skies for six Chilean cities: clear (c), clear turbid (ct), overcast (o), intermediate (i). (Source: own elaboration, 2014)

\begin{tabular}{|c|c|c|c|c|c|c|}
\hline CITIES & (c) & (ct) & $\begin{array}{l}\text { PAIR } \\
\text { (c)(ct) }\end{array}$ & (o) & (i) & $\begin{array}{l}\text { PAIR } \\
\text { (o)(i) }\end{array}$ \\
\hline $\begin{array}{l}\text { IQUIQUE } \\
\text { 2025'S/7013'W }\end{array}$ & $12 \%$ & $27 \%$ & $39 \%$ & $27 \%$ & $34 \%$ & $61 \%$ \\
\hline $\begin{array}{l}\text { ANTOFAGASTA } \\
23 \div 43 \text { 'S/7043' } \mathrm{W}\end{array}$ & $30 \%$ & $25 \%$ & $55 \%$ & $17 \%$ & $28 \%$ & $45 \%$ \\
\hline $\begin{array}{l}\text { SANTIAGO } \\
\text { 3326'S/7039' W }\end{array}$ & $19 \%$ & $22 \%$ & $41 \%$ & $30 \%$ & $29 \%$ & $59 \%$ \\
\hline $\begin{array}{l}\text { CONCEPCIÓN } \\
36946 \text { 'S/730' } \mathrm{W}\end{array}$ & $14 \%$ & $21 \%$ & $35 \%$ & $32 \%$ & $32 \%$ & $65 \%$ \\
\hline $\begin{array}{l}\text { COYHAIQUE } \\
45 \div 23 \text { 'S/7204'W }\end{array}$ & $15 \%$ & $18 \%$ & $33 \%$ & $36 \%$ & $31 \%$ & $67 \%$ \\
\hline $\begin{array}{l}\text { PUNTA ARENAS } \\
53 \circ 9 \text { 'S/705' } \mathrm{W}\end{array}$ & $6 \%$ & $22 \%$ & $28 \%$ & $29 \%$ & $43 \%$ & $72 \%$ \\
\hline
\end{tabular}

\section{Results for predominant skies per city}

The classification of predominant skies was done for six Chilean cites: Iquique, Antofagasta, Santiago, Concepcion, Coyhaique and Punta Arenas. In Table 1 it is possible to see the average percentage of occurrence of each type of sky throughout the year, the sum per pair, clear-clear turbid and intermediate-overcast, the predominant skies and pairs stand out. The results are analyzed and presented broken down per month for each studied city.

From the evaluation of two cities in the North of Chile we can say that Iquique presents, throughout the year, a predominant intermediate sky. In the monthly analysis, it can be seen that in December, February and March the predominant skies belong to the clear/clear-turbid pair, coinciding with the summer months. The rest of the year, the city presents intermediate or overcast skies, the latter being predominant in the months from June to September, which are winter months. Iquique's climate and geographical location match the calculated skies since it is a coastal city with a marked presence of coastal trough. In Antofagasta, the predominant sky during the year is clear sky. On analyzing, month-on-month, based on pairs, it can be seen that the clear or clear turbid skies are predominant from December to May, though with a greater presence of clear skies with the exception of May, June and July which present predominant intermediate skies and where more than $50 \%$ of the days are intermediate or overcast. From September to December the skies are primarily intermediate (see Figure 2).

Santiago, the capital of Chile, presents greater variations in the predominant types of skies during the year. January and February present predominantly clear skies, in March the predominant skies are clear turbid and intermediate and in the whole of the aforementioned period there is a $50 \%$ occurrence of clear or clear turbid skies. From April, the situation changes and the intermediate-overcast pair becomes predominant until October; the month with the least sky variability is July, which presents intermediate or overcast skies $80 \%$ of the time. November and December present predominant clear-clear turbid skies, but upon analyzing the predominant sky in December we find that this is the intermediate sky. The city of Concepcion, geographically located in the middle of continental Chile, presents predominantly clear-clear turbid skies from 
December until February, which represent between $53 \%$ and $58 \%$ of the time. December presents a predominantly intermediate sky, while January and February present clear skies. From March to November, the predominant skies are those of the intermediate-overcast pair, with their peak being between May and August where low clearness skies are present for more than $80 \%$ of the time. There is a $65 \%$ chance, upon analyzing the entire year, of having a low clearness day, that is to say, intermediate or overcast (see Figure 3).

Figure 2: Frequency of occurrence of standard sky per calendar month (\%) in lquique and Antofagasta in the North of Chile.

IQUIQUE

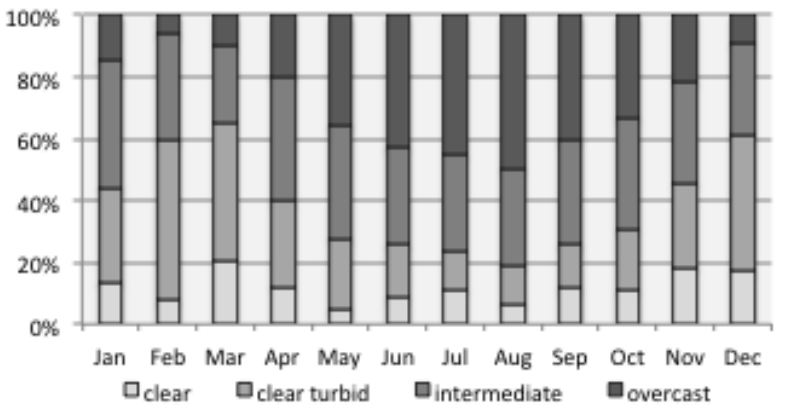

ANTOFAGASTA

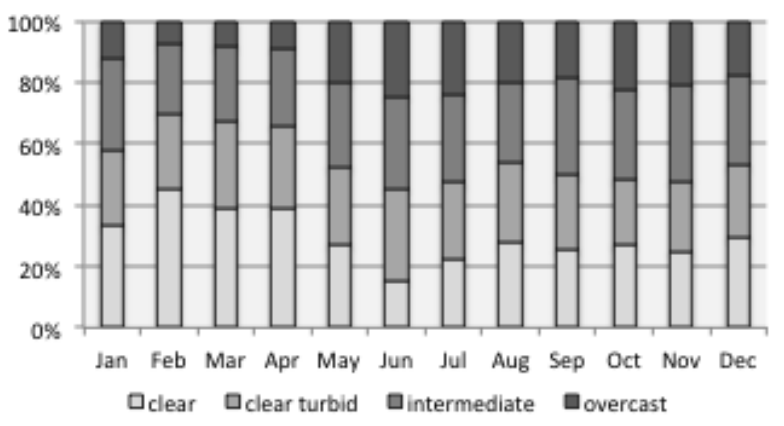

In the southernmost part of Chile, the city of Coyhaique presents, during the year, skies with low clearness for more than $60 \%$ of the time, reaching $80 \%$ in May. Overcast skies are predominant from March to December, with the exception of October where the predominant sky is intermediate with $36 \%$. Upon evaluating the entire year, approximately one third of the time there is intermediate, overcast and clear-clear turbid sky.

Finally, Chile's southernmost city, Punta Arenas, presents predominantly intermediate skies throughout the year, which on average represent $43 \%$ of the sky probabilities. On evaluating the intermediate and overcast skies set, these represent $72 \%$ of the time in the area. The months which are more likely to have overcast or intermediate skies are April and May, which present more than $80 \%$ of occurrence probability (see Figure 4).

The definition of the skies allows guiding the designers when choosing the design strategies to apply in their projects and to choose the most appropriate indicators to evaluate the proposed design strategies. We can say that, in those places where the predominant sky is overcast, the strategies being applied must allow capturing more light; we can also use the daylight factor as a metric to evaluate our design strategies. In those cities where the predominant sky type is clear or clear turbid we will apply solar protection strategies, having to evaluate the effectiveness of the strategy applied for those skies.

Figure 3: Frequency of occurrence of standard sky per calendar month (\%) for Santiago and Concepción. (Source: own elaboration, 2014)

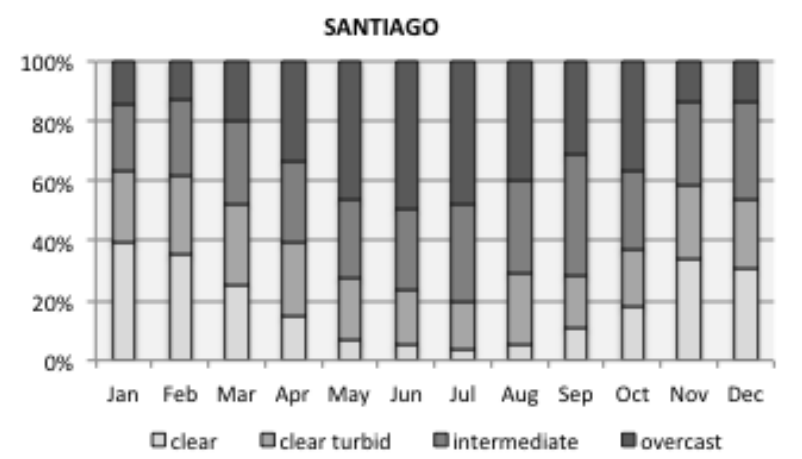

CONCEPCIÓN

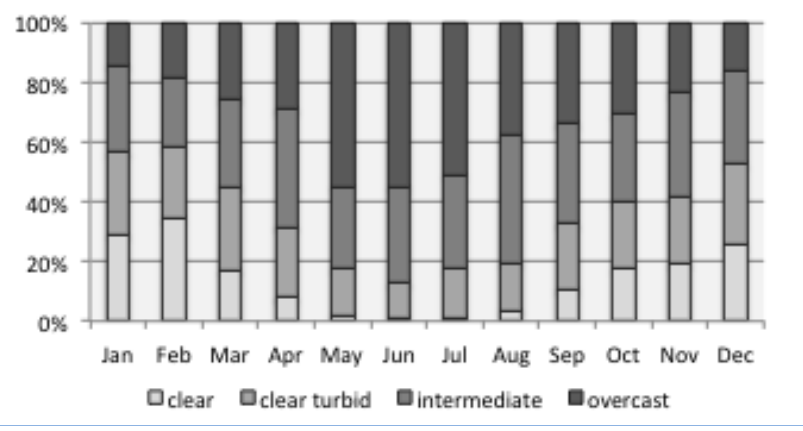

Figure 4: Frequency of occurrence of standard sky per calendar month (\%) for Coyahique and Punta Arenas. (Source: own elaboration, 2014)

COYHAIQUE

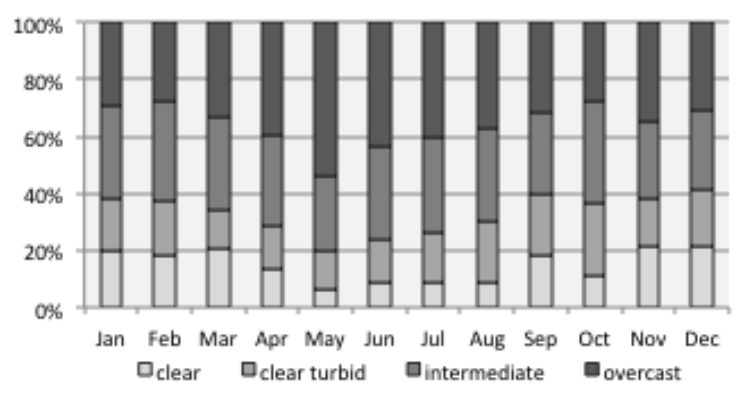

PUNTA ARENAS

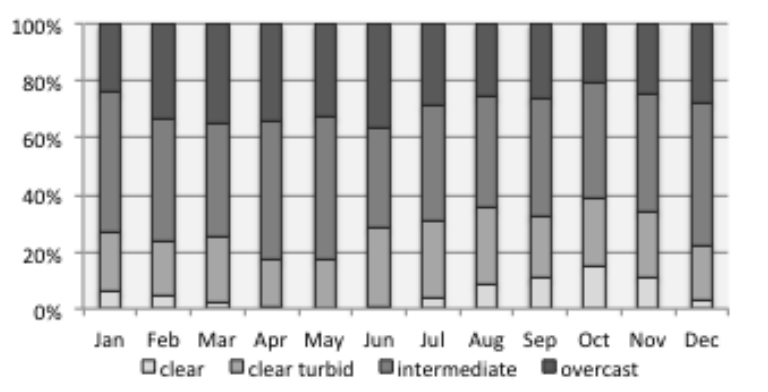




\section{Sky luminance maps with High Dynamic} Range (HDR) images

Within the framework to define methods and evaluate skies onsite, in an exploratory fashion we proceeded to measure the skies through the High Dynamic Range (HDR) photographic method, which allows instantaneously recording the luminance distribution of the different skies. Simultaneously, the Horizontal Global illuminance and the Horizontal Diffuse Illuminance were measured, and starting from this data, the skies were classified according to Perez's model.

The High Dynamic Range (HDR) method consisted in taking a series of photographs which captured the luminosity in a wide range with a conventionally calibrated photographic camera, which allows building luminous maps of the different light scenarios, exterior or interior, through a technique developed and proven by several researchers (Anaokar \& Moeck, 2005; Inanici, 2006; 2010). Different laboratory tests and studies carried out have shown than the values captured in each pixel of an HDR image correspond, precisely, to the physical characteristics of the real luminance of the capture seen (Inanici, 2010); also, this technique allows capturing the direct light coming from the sun and the diffuse light coming from the sky.

Traditional imaging methods (consumer-grade cameras), called low dynamic range (LDR), like .jpg format, are usually constrained by limitations in technology -8 bits per color channel or pixel. With these images much of the luminance information available in a scene is lost. With the HDR images, like .pic and .hdr format, real-world lighting can be captured; both very dark and very bright areas can be stored at the same time (Tyukhova, Y., \& Waters, C. 2014).

The technique consists on taking a sequence of Low Dynamic Range (LDR) images with different exposures, through which an HDR image is built. The key lies in selecting the sequence of images according to the place's luminosity, given by the exposure times and the opening degree of the shutter (Stumpfel, 2004). In this case, filters were used when there was the influence of direct sunlight; also, vignetting correction was applied according to the lens' projection angle, which required paying attention to each stage as can be seen in Figure 5 and, later, the applied technical aspects are described.

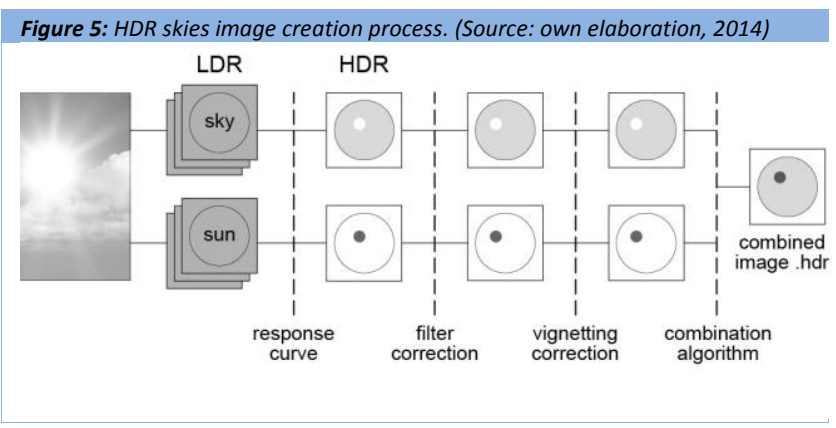

Capturing Low Dynamic Range Photographs

The Low Dynamic Range (LDR) photographs were taken in .jpg format and were later converted into HDR images with .hdr format using the Radiance software. In the case of clear skies with sun, two series of images were taken: one series of LDR photographs which allows capturing the sky's luminance and another one which allows capturing the sun's luminance. An $\mathrm{f} / 4$ opening was used to capture the luminance of the sky and an f/16 opening to capture the sun's luminance. In both series', to avoid the saturation of the photographs due to high luminance, it was necessary to use a Neutral Density KODAK 3.0 filter installed between the lens and the camera. In those places where the overcast sky is predominant, the opening was set at $f / 5.6$ with no filter. For all the series', the photographs exposure was adjusted between 5 seconds and $1 / 800$ of a second and between 8 and 15 stops. The stops were adapted from what literature recommends (1 stop), instead $11 / 3$ stop was used to get the broad range of luminance of the skies in Chile and to have the different takes required to convert the LDR to HDR images. The capture was done hourly between $8 \mathrm{am}$ and $6 \mathrm{pm}$ for one day on different dates in each city.

The acquisition of the photographs with multiple exposures was done with a Canon E05 5D Mark II model digital camera (body) and a SIGMA $8 \mathrm{~mm}$ F3.5 fisheye lens (180) with equidistant or equiangular projection properties, mounted on a tripod oriented at 90 . For a more precise handling of the exposure and opening ranges of the camera, an automatic trip (software), that allowed keeping the camera static when taking the photographs and programming series of shots, was programmed. During the capture of the sky images, two horizontal illuminance meters were installed (Minolta TS10), on a horizontally leveled tripod, in order to measure the global and diffuse illuminance, allowing us to determine the direct illuminance to then determine the type of sky.

\section{Image conversion from LDR to HDR}

Once the different series of photographs were captured, the LDR images were converted into HDR images. This process was applied to all the photograph series captured for the six studied cities. For each photographed hour, between 8 and 11 photographs were selected through a Matlab script which carried out the reading of the RGB values of each pixel; the categorization was done considering that the darkest exposure of the sequence should not have RGB values above 200 and that the brightness exposure should not have RGB values below 20 (Jacobs, 2011).

With the sequence of LDR photographs selected, these were merged with hdrgen in Radiance. In this process the application of camera calibration according to the model (Canon E05 5D Mark II fisheye lens) had to be done, to accurately measure the luminance values.

The camera's calibration was done with the capture of a series of LDR photographs under stable sky conditions verified with a luxmeter. The photographs were later converted from LDR to HDR, then the pixels were read obtaining the camera response curve, which is a polynominal value found as a saved coefficient in an ".rsp" file with three lines: one for Red, one for Green and one for Blue (RGB), as shown in Table 2. There, the luminance values are determined by equation 2 . 
Once the HDR images of each series ( $f / 4$ and $f / 16)$ were calibrated, the filter correction was done since this reduces the luminance of the photographs. The correction factor of the neutral density filter was determined by comparing the pixel values of the two HDR photographs of the Macbeth Color Chart (Lalonde, Narasimhan, \& Efros, 2009), one series with filter and another without it. The RGB values of each pixel of the photographs were obtained with MATLAB, determining the transformation factor obtained from the differences of RGB values of the two HDR photographs.

Next, the vignetting of the fisheye lens was corrected since a notorious vignetting effect takes place in the center of the image. This has an affect when increasing the errors of the peripheral pixels (Inanici \& Galvin, 2004). The vignetting mainly depends on the opening, so correction values for vignetting for $f / 4, f / 16$ and $f / 5.6$ were used, which were determined in the laboratory of the Belgium Building Research Institute (BBRI) (Cauwerts, Deneyer, \& Bodart, 2012). The vignetting effect was corrected in each HDR photograph resulting from each series of images from the skies with sun (f/4 and $f / 16)$ and the photographs of overcast skies (f/5.6).

The combination of the two HDR unvignetted images of the overcast sky layer $(f / 4)$ with the sun layer $(f / 16)$ to obtain a single luminance image with the entire sky was done with the pcomb program of Radiance. For their combination, the higher luminance from the picture with the smaller opening $(f / 16)$, the sun luminance, was taken from where the luminance above $2,000,000 \mathrm{~cd} / \mathrm{m}^{2}$ was extracted. From the image with a larger opening $(f / 4)$, the sky dome luminance, the luminance below $40,000 \mathrm{~cd} / \mathrm{m}^{2}$ was extracted. The luminance in the range between $40,000 \mathrm{~cd} / \mathrm{m}^{2}$ and $2,000,000$ $\mathrm{cd} / \mathrm{m}^{2}$ were linearly combined (Cauwerts, 2012).

Once the HDR images resulting from the different skies were obtained, the luminance maps were created which allowed knowing the distribution and luminance values of each one of the measured skies. These luminance maps allow visualizing the variations and distribution of the sky in different moments, thus allowing us to obtain from them, the illuminance distribution values for each studied city.

\section{Global and Diffuse Illuminance Measurements}

The measurements of Horizontal Global Illuminance and Horizontal Diffuse Illuminance were simultaneously taken with the luxmeter, in order to determine the type of sky according to the model developed by Perez (Perez et al., 1990). The progression of the sun and its position in the sky dome were considered, describing the amount of horizontal illuminance in the sky. With the base data measured, the epsilon $(\varepsilon)$ coefficient was determined, which is the sky's clearness, thus classifying the skies according to the defined intervals: overcast sky (first interval $\varepsilon<1,065$ ), intermediate sky (second to fifth intervals $\varepsilon>1,065<2,800$ ), clear turbid sky (sixth interval $\varepsilon>2,800<4,500$ ) and clear sky (seventh - eighth intervals $\varepsilon>4,500$ ) (Ineichen, Pierre; Molineaux, Benoit; Perez, 1994).

Starting from the measurements made, it is possible to determine to which type of sky each of the measurement moments of the six studied cities belongs to. The results obtained are summarized in Table 3 where the resulting HDR images, the measured horizontal illuminance values and the calculations to define the types of skies are shown.
Luminance $=a \times 4+b \times 3+c \times 2+d x+e$

Table 2: Curve coefficients of Canon 5D with Sigma $8 \mathrm{~mm}$ filter (Source: own elaboration, 2014).

CANON5D-MarkII-Sigma8mm.rsp under clear turbid sky 80000lx

\begin{tabular}{l|l|l|l|l}
\hline $\mathrm{a}$ & $\mathrm{b}$ & $\mathrm{c}$ & $\mathrm{d}$ & $\begin{array}{l}\mathrm{e} \\
\text { (constant) }\end{array}$ \\
\hline 3.0214 & -3.51825 & 1.42691 & 0.066276 & 0.00366741 \\
\hline 2.93034 & -3.37678 & 1.36407 & 0.0792213 & 0.00315351 \\
\hline 2.71836 & -2.9461 & 1.13621 & 0.0891981 & 0.00232806 \\
\hline
\end{tabular}

Conclusions

In terms of the metrics to quantify the daylight contributions, we conclude that using those in the Climate Based Daylight Modeling (CDBM) will allow us to obtain more accurate results confined to the place. If our objective is to quickly evaluate design strategies in the draft, these can take a long time to calculate, so knowing the predominant skies of the different cities allows us to focus our evaluation on the predominant sky in each one of the moments and seasons of the year that we wish to study. This would allow carrying out a revision of our passive strategies applied to daylight more quickly and delimited to the skies of that city. In those cities where the predominant skies are the overcast or cloudy ones, we can use the daylight factor as a metric to measure the daylight contribution, simplifying the calculations and reducing the time of analysis. The information obtained from the predominant skies, month-on-month, allows us to strengthen the scientific data for daylight and it is feasible to apply the methodology used to other places.

As for the HDR method, although the results presented were obtained with a limited number of measurements, covering only one day of the year for each city, the objective of exploring and applying the method for instant measurements was fulfilled. This method, in its early stage - the acquisition of the LDR images - is quick and simple, but in the later stage - conversion from LDR to HDR -, this becomes more complex and requires a greater precision and constant revision. In those places where the clear sky is predominant, it is necessary to check the type of filter since in the photographs, to capture the sky luminance $(f / 4)$ with the filter used, it was very difficult to achieve a broad range of images because of the clearness and sharpness of the sky, having to increase the stops. Another important process to revise is the determination of the filter factor carrying out a constant revision since there are sunspots. The capture of LDR images presents the difficulty of choosing the exposure times and the stops of each image, in those extreme places where there are strong winds and where the movement of the clouds makes capturing LDR images difficult when we had larger openings.

The measurement of the horizontal and global illuminance of the skies is a simple measurement method to be applied so that, with these lux values, we can determine the Normal Direct Illuminance and the epsilon values to determine the type of sky. This can likewise be applied to the lighting studies, since these values can be integrated in Radiance's gendaylit to carry out the study with real sky values. 


\section{Acknowledgments}

The authors would like to thank the support of CONICYT Chile (National Commission for Scientific and Technological Research) through the Fondecyt $\mathrm{N}^{\circ} 11121608$ : "Bases Cientificas para el Analisis Dinámico de la lluminación Natural en Aulas Escolares".

\section{References}

Anaokar, S., \& Moeck, M. (2005). Validation of High Dynamic Range Imaging to Luminance Measurement. LEUKOS, 2(2), 133144. doi:10.1582/LEUKOS.2005.02.02.005

Andersen, M., Kleindienst, S., Yi, L., Lee, J., Bodart, M., \& Cutler, B. (2008a). Informing daylighting design with the Lightsolve approach: why and how. $25^{\text {th }}$ Conference on Passive and Low Energy Architecture, Dublin.

Andersen, M., Kleindienst, S., Yi, L., Lee, J., Bodart, M., \& Cutler, B. (2008b). An intuitive daylighting performance analysis and optimization approach. Building Research \& Information, 36(6), 593-607. doi:10.1080/09613210802243159

Anderson, K. (2014). Design Energy Simulation for Graphics: Guide to 3D Graphics. New York: Routledge.

Cauwerts, C. (2012). Potential of image-based lighting (IBL) pictures for subjective lighting quality evaluations a comparison with real world luminances and physically based renderings (PBR). $11^{\text {th }}$ Annual International Radiance Workshop, Copenhagen

Cauwerts, C., Deneyer, A., \& Bodart, M. (2012). Vignetting Effect Of Two Identical Fisheye Lenses. LEUKOS, 8(3), 181-184.

Commission International de l'Eclairage. (2003). Spatial Distribution of Daylight-CIE Standard General Sky. CIE Publication No. S 011/E.

Hopkinson, R. G., Petherbridge, P., \& Longmore, J. (1966) Daylighting. London: Heinemann.

Igawa, N., Nakamura, H., Matsuura, K., (1997). Sky Luminance Distributuion Model For Simulation Of Daylit Environment, IBPSA International Building Performance Simulation Conf., Prague.

Inanici, M. N. (2006). Evaluation of high dynamic range photography as a luminance data acquisition system. Lighting Research and Technology, 38(2), 123-134.

Inanici, M. (2010). Evalution of High Dynamic Range Image-Based Sky Models in Lighting Simulation. LEUKOS, 7(2), 69-84. doi:10.1582/LEUKOS.2010.07.02001

Inanici, M., \& Galvin, J. (2004). Evaluation of High Dynamic Range Photography as a Luminance Mapping Technique LBNL Report \# 57545, Lawrence Berkeley National Laboratory. Web http://escholarship.org/uc/item/9h61f5h8 (visited 01 jan 2014).

Jacobs, A. (2011). WebHDR-Jaloxa. http://www.jaloxa.eu/webhdr/ (01 jan 2014).

Kleindienst, S., Bodart, M., Andersen, M. (2008). Graphical Representation of Climate-Based Daylight Performance to Support Architectural Design. LEUKOS, 5(1), 39-61. doi:10.1582 /LEUKOS.2008.05.01.003

Lalonde, J., Narasimhan, S., \& Efros, A. (2009). What Do the Sun and the Sky Tell Us About the Camera? International Journal of Computer Vision, 88(1), 24-51. doi:10.1007/s11263-009-0291-4
Mardaljevic, J., Andersen, M., Roy, N., Christoffersen, J., Gateway, T., Enac, E., \& Lipid,. (2012). Daylighting Metrics: Is There A Relation Between Useful Daylight Illuminance And Daylight Glare Probability? Building Simulation and Optimization Conference. Loughborough, UK.

Moon, P.; Spencer, D. (1942). Illumination from a Nonuniform Sky. Illuminating Engineering, Vol 37(10), 707-726.

Nabil, A., \& Mardaljevic, J. (2006). Useful daylight illuminances: A replacement for daylight factors. Energy and Buildings, 38(7), 905-913. doi:10.1016/j.enbuild.2006.03.013

Perez, R., Ineichen, P., Seals, R., Michalsky, J., \& Stewart, R. (1990). Modeling daylight availability and irradiance components from direct and global irradiance. Solar Energy, 44(5), 271-289.

Perez, R., Seals, R., \& Michalsky, J. (1993). All-Weather Model For Sky Luminance Distribution-Preliminary Configuration And Validation. Solar Energy, 50(3), 235-245.

Reinhart, C., Mardaljevic, J., \& Rogers, Z. (2006). Dynamic Daylight Performance Metrics for Sustainable Building Design. LEUKOS, 3(1), 7-31. doi:10.1582/LEUKOS.2006.03.01.001

Stumpfel, J.; Tchou, C; Jones, A; Hawkins, T; Wenger, A and Debevec, $P$ (2004). Direct HDR Lighting Capture of the Sun and Sky. In Proceedings of the AFRIGRAPH 04, Africa.

Tyukhova, Y., \& Waters, C. (2014). An Assessment of High Dynamic Range Luminance Measurements with LED Lighting. LEUKOS, 10(2), 87-99.

Waldram, P J. (1950). A Measuring Diagram for Daylight Illumination. London: B T Batsford Ltd. 
Table 3: HDR Photographs of the six studied cities, measurements and calculations of illuminances values. (Source: Self-Elaboration, 2014)
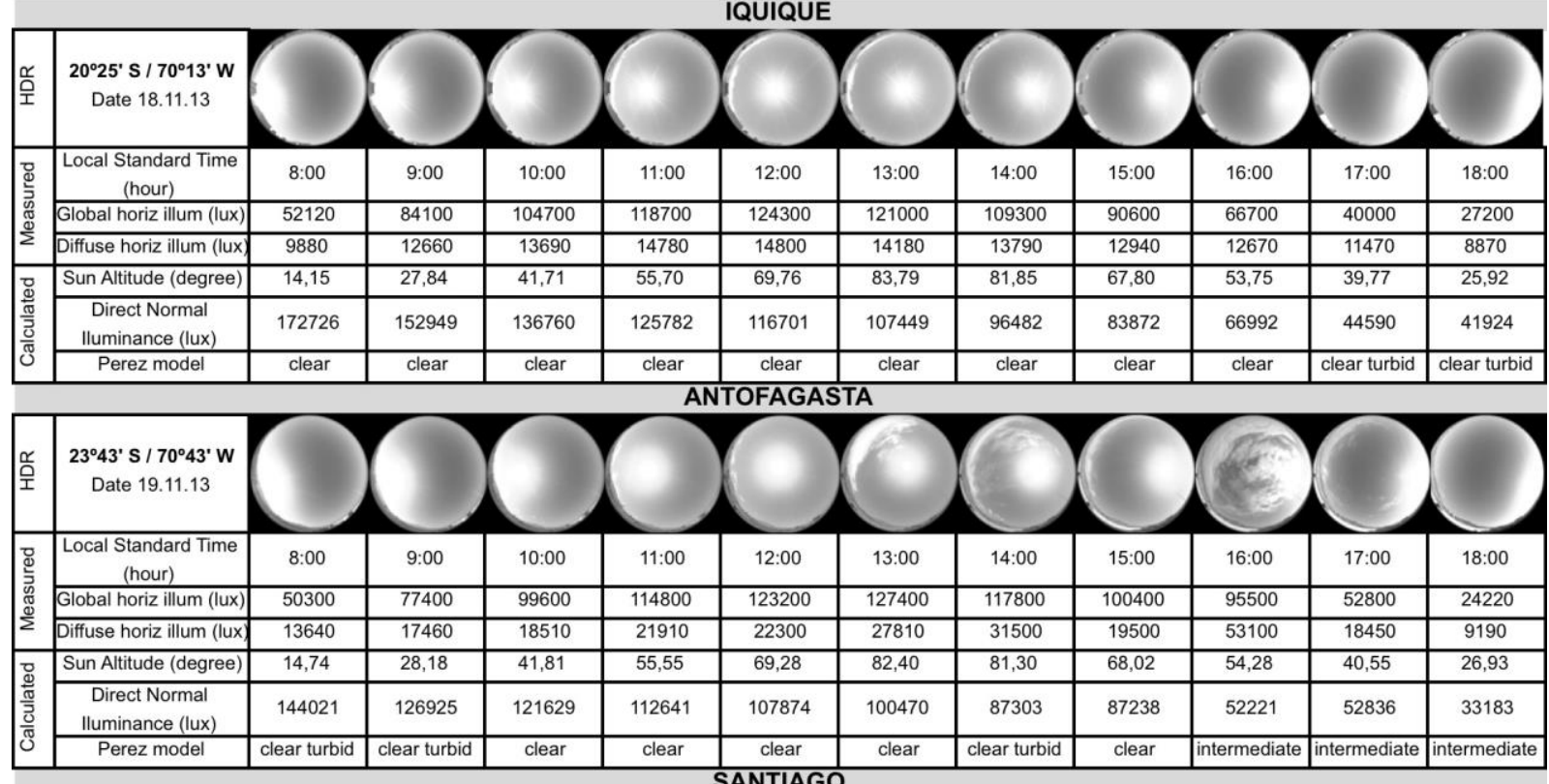

\begin{tabular}{|c|c|c|c|c|c|c|c|c|c|c|c|c|}
\hline $\begin{array}{l}\text { 옴 } \\
\text { 이 }\end{array}$ & $\begin{array}{c}\mathbf{3 3}^{\circ} \mathbf{2 6} \mathbf{\prime}^{\prime} \mathbf{S} / \mathbf{7 0}^{\circ} 39^{\prime} \mathbf{W} \\
\text { Date } 21.03 .14\end{array}$ & & & & & & & & & & & \\
\hline \multirow{3}{*}{ 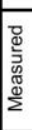 } & $\begin{array}{c}\text { Local Standard Time } \\
\text { (hour) }\end{array}$ & 8:00 & 9:00 & 10:00 & $11: 00$ & $12: 00$ & 13:00 & $14: 00$ & $15: 00$ & $16: 00$ & $17: 00$ & 18:00 \\
\hline & Global horiz illum (lux) & 3021 & 26450 & 51700 & 71800 & 88100 & 93900 & 92900 & 89400 & 76100 & 55700 & 31500 \\
\hline & Diffuse horiz illum (lux) & 1924 & 6950 & 9170 & 10940 & 13110 & 14530 & 15950 & 11300 & 10810 & 11380 & 8560 \\
\hline \multirow{3}{*}{ 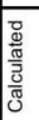 } & Sun Altitude (degree) & 1,98 & 14,44 & 26,56 & 37,93 & 47,76 & 54,65 & 56,65 & 52,96 & 44,97 & 34,56 & 22,90 \\
\hline & $\begin{array}{c}\text { Direct Normal } \\
\text { Iluminance (lux) }\end{array}$ & 31738 & 78197 & 95091 & 99003 & 101286 & 97309 & 92111 & 97834 & 92367 & 78122 & 58944 \\
\hline & Perez model & clear turbid & clear turbid & clear & clear & clear & clear & clear & clear & clear & clear & clear turbid \\
\hline
\end{tabular}

\begin{tabular}{|c|c|c|c|c|c|c|c|c|c|c|c|c|}
\hline $\begin{array}{l}\frac{\alpha}{0} \\
\text { 으 }\end{array}$ & $\begin{array}{c}36^{\circ} 46^{\prime} \mathrm{S} / \mathbf{7 3}^{\circ} 03^{\prime} \mathrm{W} \\
\text { Date } 25.03 .14\end{array}$ & & & & & & & & & & & \\
\hline \multirow{3}{*}{ 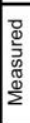 } & $\begin{array}{l}\text { Local standard time } \\
\text { (hour) }\end{array}$ & $8: 00$ & 9:00 & 10:00 & $11: 00$ & $12: 00$ & 13:00 & $14: 00$ & 15:00 & $16: 00$ & $17: 00$ & 18:00 \\
\hline & Global horiz illum (lux) & 1510 & 16770 & 39300 & 57700 & 57900 & 65200 & 88300 & 83400 & 72400 & 55600 & 35100 \\
\hline & Diffuse horiz illum (lux) & 927 & 4530 & 7640 & 11010 & 12620 & 14300 & 10260 & 8920 & 8440 & 8230 & 7290 \\
\hline \multirow{3}{*}{ 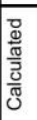 } & Sun altitude (degree) & - & 11,34 & 22,91 & 33,66 & 42,88 & 49,41 & 51,75 & 49,18 & 42,50 & 33,18 & 22,38 \\
\hline & $\begin{array}{l}\text { Direct Normal } \\
\text { iluminance(lux) }\end{array}$ & - & 62242 & 81328 & 84225 & 66531 & 67027 & 99362 & 98408 & 94663 & 86538 & 73038 \\
\hline & Perez model & clear & clear & clear & clear & clear turbid & clear turbid & clear & clear & clear & clear & clear \\
\hline
\end{tabular}

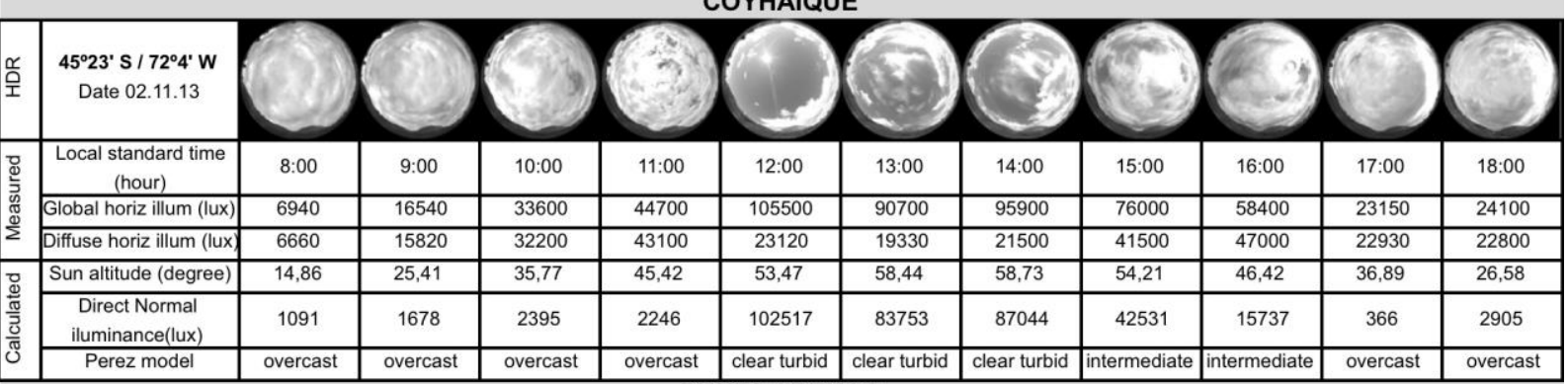

\begin{tabular}{|c|c|c|c|c|c|c|c|c|c|c|c|c|}
\hline \multicolumn{13}{|c|}{ PUNTA ARENAS } \\
\hline $\begin{array}{l}\stackrel{\alpha}{0} \\
\underline{\underline{T}}\end{array}$ & $\begin{array}{c}\mathbf{5 3}^{\circ} \mathbf{9}^{\prime} \mathbf{S} / \mathbf{7 0}^{\circ} \mathbf{5} \mathbf{5}^{\prime} \mathbf{W} \\
\text { Date } 01.11 .13\end{array}$ & & & & & & & & & & & \\
\hline \multirow{3}{*}{ 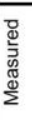 } & $\begin{array}{c}\text { Local standard time } \\
\text { (hour) }\end{array}$ & $8: 00$ & 9:00 & $10: 00$ & $11: 00$ & $12: 00$ & $13: 00$ & $14: 00$ & $15: 00$ & $16: 00$ & $17: 00$ & $18: 00$ \\
\hline & Global horiz illum (lux) & 39900 & 45900 & 62200 & 77500 & 84700 & 72100 & 93200 & 86000 & 64100 & 63200 & 47500 \\
\hline & Diffuse horiz illum (lux) & 7490 & 9030 & 18040 & 11040 & 24940 & 37400 & 27900 & 13480 & 34500 & 15800 & 13050 \\
\hline \multirow{3}{*}{ 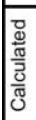 } & Sun altitude (degree) & 16,38 & 25,18 & 33,59 & 41,06 & 46,81 & 49,92 & 49,69 & 46,17 & 40,13 & 32,49 & 24,00 \\
\hline & $\begin{array}{l}\text { Direct Normal } \\
\text { iluminance(lux) }\end{array}$ & 114885 & 86658 & 79813 & 101176 & 81958 & 45347 & 85631 & 100522 & 45920 & 88221 & 84679 \\
\hline & Perez model & clear & clear & clear turbid & clear & clear turbid & intermediate & clear turbid & clear & intermediate & clear turbid & clear turbid \\
\hline
\end{tabular}

